\title{
Validation of ICESat-2 Surface Water Level Product ATL13 with Near Real Time Gauge Data
}

\author{
Giribabu Dandabathula*, Sitiraju Srinivasa Rao \\ Regional Remote Sensing Centre-West, National Remote Sensing Centre, Indian Space Research Organization, Jodhpur, Rajasthan, India
}

\section{Email address:}

dgb.isro@gmail.com (G. Dandabathula)

${ }^{*}$ Corresponding author

\section{To cite this article:}

Giribabu Dandabathula, Sitiraju Srinivasa Rao. Validation of ICESat-2 Surface Water Level Product ATL13 with Near Real Time Gauge Data. Hydrology. Vol. 8, No. 2, 2020, pp. 19-25. doi: 10.11648/j.hyd.20200802.11

Received: July 23, 2020; Accepted: August 3, 2020; Published: August 13, 2020

\begin{abstract}
The NASA's Ice, Cloud, and land Elevation Satellite (ICESat) mission uses laser altimetry measurements to determine the elevations at point levels of Earth. ICESat-2, which is a successor to the ICESat-1 satellite mission is a continuation of this series and carries a sensor namely Advanced Topographic Laser Altimeter System (ATLAS). The key advancement of ICESat-2 is that it generates individual laser foot prints of nearly $14 \mathrm{~m}$ (in diameter) on the Earth's surface, with each footprint separated by only $70 \mathrm{~cm}$, a much higher resolution and sampling than the earlier mission. ATLAS works under the concept of multi-beam approach containing three pairs of strong and weak beams that produce data products containing global geolocated photon data and height data from land-ice, sea-ice, land/terrain, canopy, ocean surface, and inland water-bodies. From the Level 2 master product called ATL03 numerous sub-data product are generated and are made available to the public through the National Snow and Ice Data Center. One of the products namely ATL13 is a specialized geophysical data product that gives along-track and near-shore water surface height distribution within the water masks. In this article, results after validating ATL13 data product with 46 observations made with near real-time gauged data for 15 reservoirs/water bodies have been presented. The maximum uncertainty observed for this data product is at centimeter-level. A significant observation made from this study is that the heights of surface water level computed from strong beams (gt1r, gt2r, and gt3r) and weak beams (gt1l, gt2l, and gt3l) are occasionally having a variation of 5 to 10 centimeters relatively.
\end{abstract}

Keywords: Surface Water Level, ICESat-2, ATL13, Laser Altimetry, Photon

\section{Introduction}

The NASA's Ice, Cloud, and land Elevation Satellite (ICESat) mission uses laser altimetry measurement to determine the elevations at point levels of Earth [1]. The recent version in this series namely ICESat-2 carries a single instrument, the Advanced Topographic Laser Altimeter System (ATLAS). The key advancement of ICESat-2 is that it generates individual laser foot print of nearly $14 \mathrm{~m}$ (in diameter) on the Earth's surface, with each footprint separated by only $70 \mathrm{~cm}$, a much higher resolution and sampling than the earlier mission. ATLAS works under the concept of multi-beam approach that produces data products containing global geolocated photon data and height data from land-ice, sea-ice, land/terrain, canopy, ocean surface, and inland water-bodies [2]. The working mechanism and other intricate details about the advancements in ICESat-2 have been mentioned by Markus et al. [1]. Essentially, the multi-beam approach in ICESat-2 consists of a six beam of three pairs acquisition system. These beams are separated by a cross-track interval of nearly $3 \mathrm{~km}$ and for each beam pair, a strong and weak beam is located at a distance of $90 \mathrm{~m}$.

Space-borne based measurement of terrestrial surface water level remains a challenging task but at the same time, it is of great need to model the global water and energy cycles, detect the water-level changes which in turn addresses the issues like susceptibility of life due to flood hazards. Alsdorf et al. have surveyed the space-borne methods to compute the water levels and highlighted the viability of using altimetry based methods for collecting levels of water surfaces [3].

ICESat-2 mission disseminates numerous levels of data products to the scientific fraternity and one of the geophysical products namely ATL13 is a specialized data product that gives along-track and nearshore water surface height distribution 
within water masks $[1,4]$. Justification, goals and definition of the inland water body height data product aka ATL13 has been mentioned by Jasinki et al. in the Algorithm Theoretical Basis Document (ATBT) [4]. An ATL13 data product is available for most of the inland water bodies with an area greater than about $0.01 \mathrm{~km}^{2}$, rivers greater than about $100 \mathrm{~m}$, transitional water including estuaries and bays, and near short $7 \mathrm{~km}$ buffer [4]. The along-track water surface height essentially reports elevations as orthometric height above WGS84 ellipsoid in meters using an attribute namely 'ht_ortho' for six ground tracks (viz. strong tracks - gt1r, gt2r, gt3r and weak tracks - gt11, gt2l gt31). All these ground tracks consist of a timestamp for data acquisition.

ATL08 is one more product from ICESat- 2 that contains best-fit height above a reference ellipsoid and this product too gives the height of the water surface, but one needs to convert into ortho height to compare with the gauged data of the water body. Earlier, Dandabathula et al. assessed the performance of ICESat-2 ATL08 data product by using water level changes from two dates and compared these changes with gauged data [5]. Their study shows that the accuracy of water level from ATL08 ranges from 2 to $39 \mathrm{~cm}$ and this uncertainty has been attributed to the inherent ripples and streaks on the water body surface.

Zhang et al. used ICESat-2 ATL13 data for observing lake level and volume changes in Tibetan Plateau (where human activities are negligible) and concluded that the water surface height from ATL13 is in excellent agreement with in situ measurements for Qinghai Lake where the uncertainty is < $0.2 \mathrm{~m}$ [6]. Yuan et al. have assessed the ICESat-2 ATL13 data product's accuracy in 30 reservoirs in China and their observation of mean relative errors was $0.06 \mathrm{~m}$ [7].

In this article, we have compared the surface water height retrieved from ATL13 strong tracks and weak tracks individually for 15 reservoirs/water bodies and compared with the near real-time gauged data that are reported in the authentic bulletins.

\section{Data and Methods}

\subsection{Study Area}

A total of 15 reservoirs/water bodies distributed across the landscape of Indian sub-continent were selected for this study. The basis for selecting these study areas is such that the time of acquisition of ICESat-2 ATL13 data product matches the availability of corresponding near real-time gauged data with a permeability of eight hours variation. Figure 1 shows the reservoirs/water bodies that are selected for this investigation. The names of the reservoirs/water bodies are mentioned in table 1 .

\subsection{ATL13: Inland Water Body Height Data Product of ICESat-2}

Web-portal namely openaltimetry.com is a cyber-infrastructure platform for discovery, access, and visualization of data from NASA's ICESat and ICESat-2 missions [8]. Figure 2 shows the ground track and all the six beams of ATL13 on Nath Sagar reservoir formed by Jayakwadi Dam in India. In this study ATL13 data has been retrieved from openaltimetry web-portal in Comma Separated Values (.csv) format and migrated into the spatial domain. Mean elevation has been computed individually form strong beams and weak beams that are falling in the water body. Currently, version of the ATL13 data product is 3 and the same data has been used for this analysis.

\subsection{Gauge Data from Central Water Commission (India) Weekly Bulletins}

The Indian government is abided with the Hydro-Meteorological data dissemination policy [9, 10]. Under the aegis of this policy, Central Water Commission (CWC) releases weekly bulletins (on every Thursday) about the water storage level (gauged at 0800 Hrs.) for major reservoirs in India through the portal available at http://cwc.gov.in/reservoir-storage [11].

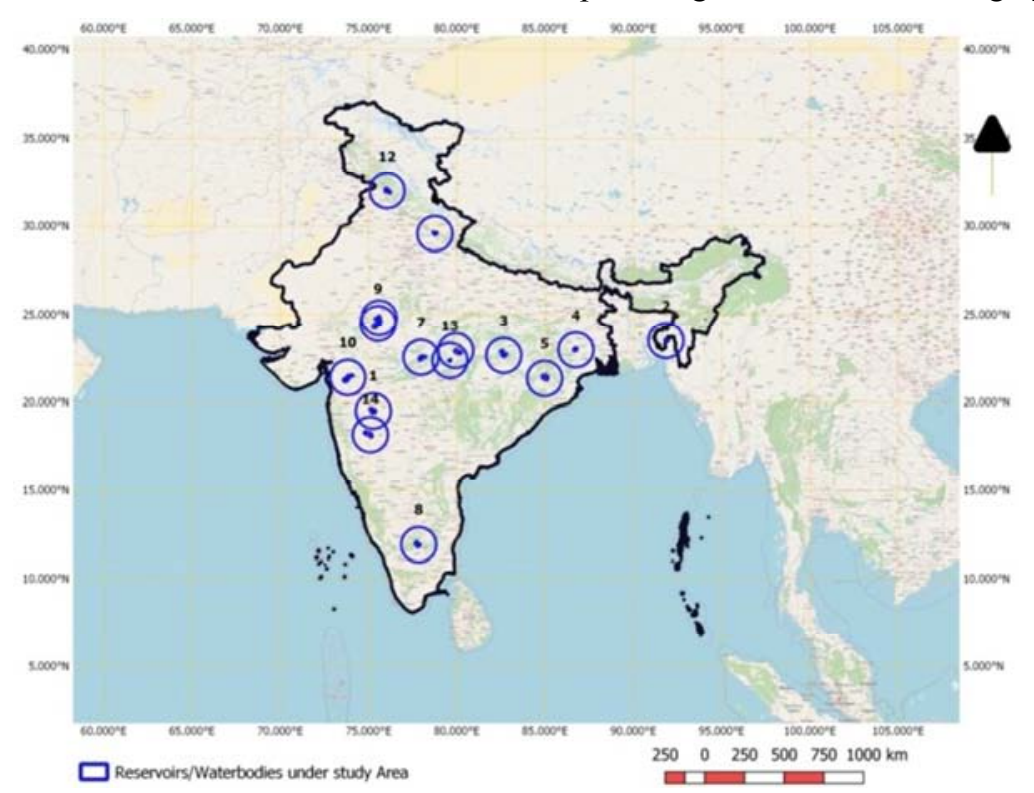

Figure 1. Location map of Reservoirs/Water bodies under the investigation. 


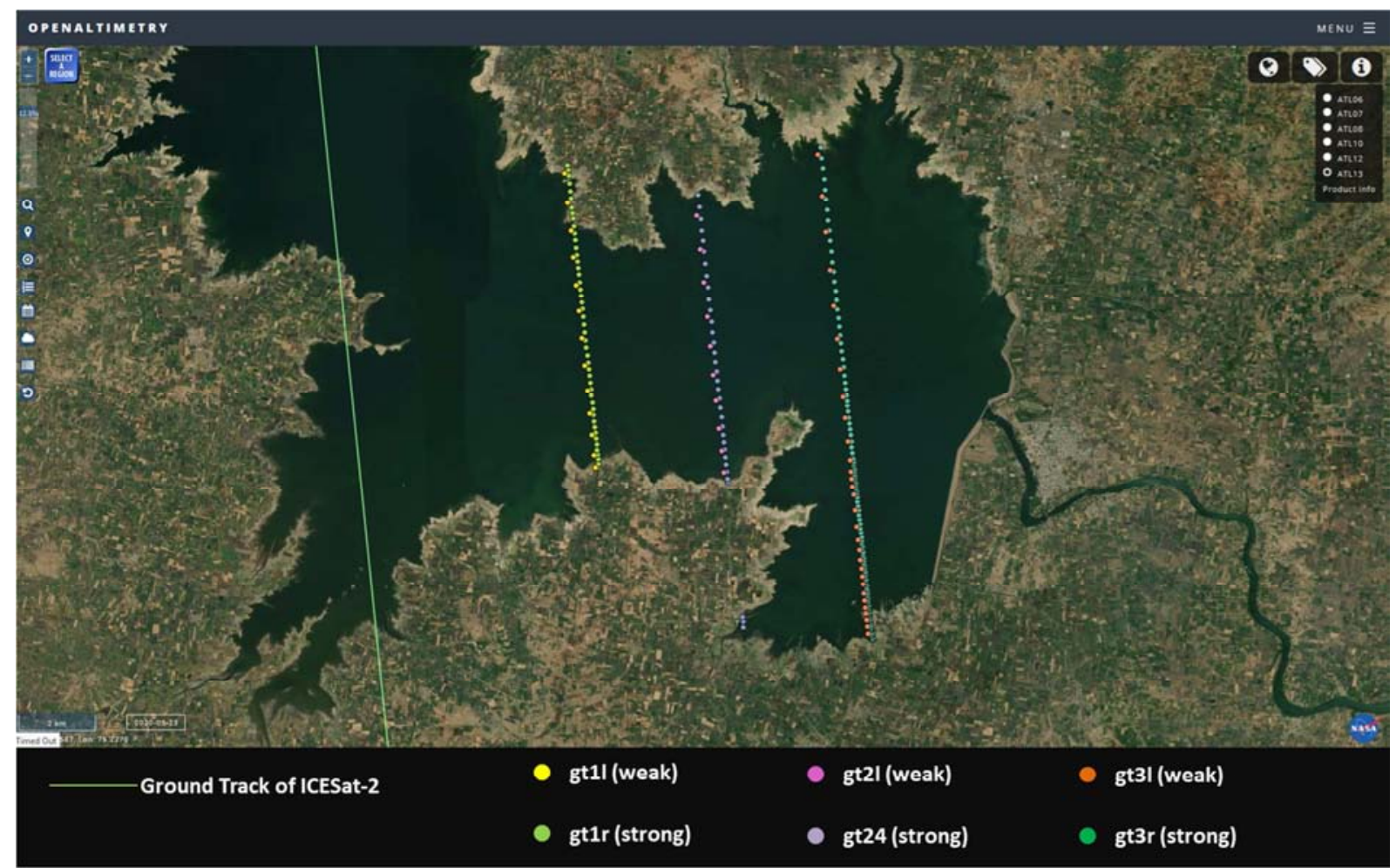

Figure 2. Ground tracks of ATL13 data product over Nath Sagar reservoir (India).

\subsection{Methodology}

Figure 3 shows the methodology that was used for this study. Initial screening of the reservoirs/water bodies has been done with the criteria that the gauged data from CWC weekly bulletins and ICESat-2 ATL13 data acquisition are closely matched in terms of time (with a permeability of $+/-8$ hours).

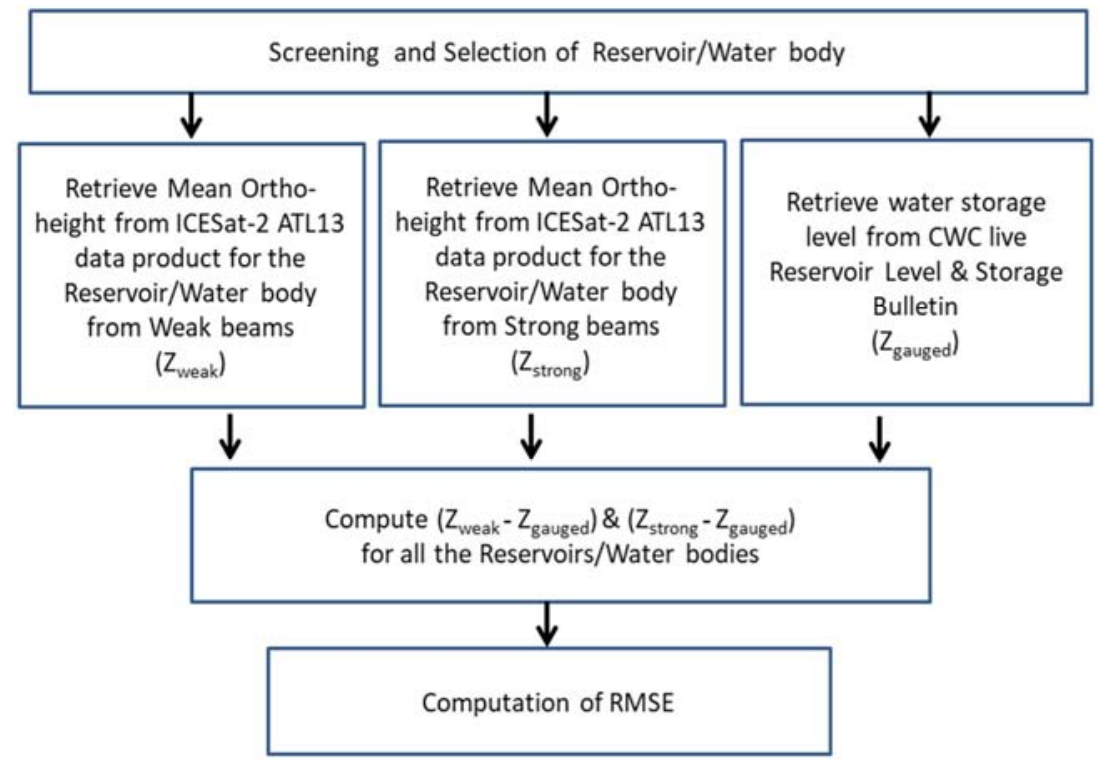

Figure 3. Methodology used for evaluating ATL13 data product.

A total of 15 reservoirs/water bodies have been selected which matched this criterion. Mean water level height has been estimated from all the available ground tracks individually from strong beams and weak beams. These heights have been compared with the gauged reservoir level is taken from the CWC gauged records and reported in the subsequent section. A total of 46 observations have been made for this analysis.

As a part of ATL13 data production, only those segments that are falling as a part of global lakes and reservoirs will be considered (E.g. HydroLakes database) [12], however, to ensure this we have manually checked the geolocation of segments by overlaying them in the corresponding Sentinel-2 data that is acquired on a nearby date. 


\section{Results}

Table 1 shows the reservoir name, the track number of ICESat-2, date of data acquisition by the ICESat-2 and the observation made by gauge data, water level retrieved from strong beam and weak beam, and the respective differences with respect to the gauged data.
Table 2 represents the observations derived from table 1 . Maximum uncertainties observed in the strong beams and weak beams are $52 \mathrm{~cm}$ and $70 \mathrm{~cm}$ respectively. Root mean square error (RMSE) represents quantitative model performance in total. The RMSE for the heights of surface water level from strong beams and weak beams are $29 \mathrm{~cm}$ and $35 \mathrm{~cm}$ respectively.

Table 1. Table showing reservoir name and corresponding observations consisting heights of surface water levels.

\begin{tabular}{|c|c|c|c|c|}
\hline Obs. No. & Name of Reservoir & ICESat-2 Track No. & Dt. Of ICESat-2 Ground Track & $\begin{array}{l}\text { Mean Height of Surface Water level from } \\
\text { Strong Beam (meters) } \boldsymbol{H}_{\text {strong }}\end{array}$ \\
\hline 1.1 & Jayakwadi & 950 & 2018-Nov-29 & 459.02 \\
\hline 1.2 & & & 2019-May-30 & 454.59 \\
\hline 1.3 & & & 2019-Aug-29 & 463.38 \\
\hline 1.4 & & & $2020-F e b-26$ & 463.03 \\
\hline 1.5 & & 508 & 2019-Oct-30 & 464.25 \\
\hline 2.1 & Gumti & 614 & 2018-Nov-07 & 92.57 \\
\hline 2.2 & & & 2019-Feb-08 & 90.455 \\
\hline 2.3 & & & 2019-May-08 & 88.41 \\
\hline 2.4 & & 1384 & 2019-Sep-26 & 90.82 \\
\hline 3.1 & Minimata Bango & 401 & 2020-Jan-21 & 357.68 \\
\hline 4.1 & Kangsabati & 96 & 2020-Apr-01 & 129.52 \\
\hline 4.2 & & 538 & 2020-Jan-30 & 130.31 \\
\hline 5.1 & Rengali & 104 & 2019-Jan-04 & 117.96 \\
\hline 5.2 & & & 2019-Oct-03 & 124.14 \\
\hline 5.3 & & & 2020-Apr-02 & 120.5 \\
\hline 6.1 & Ramganga & 767 & 2020-Feb-14 & 354.51 \\
\hline 6.2 & & 973 & 2019-May-31 & 343.54 \\
\hline 6.3 & & & 2019-Nov-29 & 357.27 \\
\hline 7.1 & Tawa & 767 & 2020-Feb-14 & 349.95 \\
\hline 7.2 & & 1095 & 2019-Jun-08 & 337.6 \\
\hline 7.3 & & & 2020-Mar-07 & 347.9 \\
\hline 8.1 & Stanley - Mettur & 272 & 2019-Apr-16 & 221.05 \\
\hline 9.1 & Gandhisagar & 1278 & 2018-Dec-12 & 390.76 \\
\hline 9.2 & & & 2020-Mar-19 & 390.73 \\
\hline 9.3 & & 508 & 2019-Jan-30 & 387.33 \\
\hline 9.4 & & & 2020-Jan-29 & 398.93 \\
\hline 10.1 & Ukai & 630 & 2019-Feb-07 & 93.09 \\
\hline 10.2 & & & 2019-May-09 & 86.63 \\
\hline 10.3 & & & 2020-Feb-05 & 103.53 \\
\hline 10.4 & & 516 & 2018-Nov-01 & 95.77 \\
\hline 10.5 & & & 2019-Jan-31 & 93.2 \\
\hline 10.6 & & & 2019-Oct-30 & 105.44 \\
\hline 11.1 & Rana Pratap Sagar & 1278 & 2020-Mar-19 & 348.25 \\
\hline 11.2 & & 508 & 2018-Oct-31 & 349.41 \\
\hline 12.1 & Pong & 714 & 2019-Feb-13 & 410.91 \\
\hline 12.2 & & & 2019-May-15 & 408.5 \\
\hline 12.2 & & 1156 & 2019-Mar-14 & 409.01 \\
\hline 13.1 & Sanjay Sarovar & 654 & 2019-Nov-08 & 519.02 \\
\hline 13.2 & & 973 & 2020-FEB-28 & 515.17 \\
\hline 14.1 & Bhima Dam & 508 & 2019-Oct-30 & 497.68 \\
\hline 14.2 & & & 2020-Jan-29 & 496.89 \\
\hline 14.3 & & 950 & 2018-Nov-29 & 494.89 \\
\hline 14.4 & & & 2019-Feb-28 & 492.5 \\
\hline 14.5 & & & 2019-May-30 & 486.18 \\
\hline 14.6 & & & 2019-Aug-29 & 497.59 \\
\hline 15.1 & Bargi & 470 & 2019-Apr-29 & 415.86 \\
\hline
\end{tabular}

Table 1. Continued.

\begin{tabular}{lllll}
\hline Obs. No. & $\begin{array}{l}\text { Mean Height of Surface Water level } \\
\text { from Weak Beams (meters) } \mathbf{H}_{\text {weak }}\end{array}$ & $\begin{array}{l}\text { Water level recorded in CWC } \\
\text { Record (meters) } \mathbf{H}\end{array}$ & $\begin{array}{l}\text { Difference of Height } \\
\left(\text { meters) }\left(\mathbf{H}_{\text {strong }}-\mathbf{H}\right)\right.\end{array}$ & $\begin{array}{l}\text { Difference of Height } \\
(\mathbf{m e t e r s})\left(\mathbf{H}_{\text {Weak }}-\mathbf{H}\right)\end{array}$ \\
\hline 1.1 & 459.03 & 458.76 & -0.26 & -0.27 \\
1.2 & 454.62 & 454.44 & -0.15 & -0.18 \\
1.3 & 463.46 & 463.06 & -0.32 & -0.4 \\
1.4 & 463.13 & 462.73 & -0.3 & -0.4 \\
1.5 & 464.25 & 463.91 & -0.34 & -0.34 \\
\hline
\end{tabular}




\begin{tabular}{|c|c|c|c|c|}
\hline Obs. No. & $\begin{array}{l}\text { Mean Height of Surface Water level } \\
\text { from Weak Beams (meters) } H_{\text {weak }}\end{array}$ & $\begin{array}{l}\text { Water level recorded in CWC } \\
\text { Record (meters) H }\end{array}$ & $\begin{array}{l}\text { Difference of Height } \\
\text { (meters) }\left(\mathbf{H}_{\text {Strong }}-\mathbf{H}\right)\end{array}$ & $\begin{array}{l}\text { Difference of Height } \\
\text { (meters) }\left(\mathrm{H}_{\text {Weak }}-\mathrm{H}\right)\end{array}$ \\
\hline 2.1 & 92.61 & 92.15 & -0.42 & -0.46 \\
\hline 2.2 & 90.49 & 90.15 & -0.305 & -0.34 \\
\hline 2.3 & 88.42 & 88.2 & -0.21 & -0.22 \\
\hline 2.4 & 90.84 & 90.5 & -0.32 & -0.34 \\
\hline 3.1 & 357.72 & 357.38 & -0.3 & -0.34 \\
\hline 4.1 & 129.82 & 129.34 & -0.18 & -0.48 \\
\hline 4.2 & 130.37 & 130.68 & 0.37 & 0.31 \\
\hline 5.1 & 118.01 & 117.77 & -0.19 & -0.24 \\
\hline 5.2 & 124.14 & 124.07 & -0.07 & -0.07 \\
\hline 5.3 & 120.6 & 120.52 & 0.02 & -0.08 \\
\hline 6.1 & 354.55 & 354.42 & -0.09 & -0.13 \\
\hline 6.2 & 343.58 & 343.22 & -0.32 & -0.36 \\
\hline 6.3 & 357.22 & 357 & -0.27 & -0.22 \\
\hline 7.1 & 349.98 & 349.91 & -0.04 & -0.07 \\
\hline 7.2 & 337.65 & 337.41 & -0.19 & -0.24 \\
\hline 7.3 & 347.98 & 347.87 & -0.03 & -0.11 \\
\hline 8.1 & 221.05 & 221.09 & 0.04 & 0.04 \\
\hline 9.1 & 390.89 & 391.2 & 0.44 & 0.31 \\
\hline 9.2 & 390.79 & 390.26 & -0.47 & -0.53 \\
\hline 9.3 & 387.41 & 387.11 & -0.22 & -0.3 \\
\hline 9.4 & 398.92 & 398.81 & -0.12 & -0.11 \\
\hline 10.1 & 93.15 & 92.98 & -0.11 & -0.17 \\
\hline 10.2 & 86.69 & 86.53 & -0.1 & -0.16 \\
\hline 10.3 & 103.61 & 103.38 & -0.15 & -0.23 \\
\hline 10.4 & 95.79 & 95.85 & 0.08 & 0.06 \\
\hline 10.5 & 93.28 & 93.08 & -0.12 & -0.2 \\
\hline 10.6 & 105.49 & 105.16 & -0.28 & -0.33 \\
\hline 11.1 & 348.34 & 347.75 & -0.5 & -0.59 \\
\hline 11.2 & 349.73 & 349.03 & -0.38 & -0.7 \\
\hline 12.1 & 411.11 & 410.64 & -0.27 & -0.47 \\
\hline 12.2 & 408.55 & 408.09 & -0.41 & -0.46 \\
\hline 12.2 & 409.32 & 408.8 & -0.21 & -0.52 \\
\hline 13.1 & 519.16 & 519.25 & 0.23 & 0.09 \\
\hline 13.2 & 515.21 & 514.65 & -0.52 & -0.56 \\
\hline 14.1 & 497.72 & 497.32 & -0.36 & -0.4 \\
\hline 14.2 & 496.82 & 496.4 & -0.49 & -0.42 \\
\hline 14.3 & 494.94 & 494.62 & -0.27 & -0.32 \\
\hline 14.4 & 492.5 & 492.21 & -0.29 & -0.29 \\
\hline 14.5 & 486.21 & 485.77 & -0.41 & -0.44 \\
\hline 14.6 & 497.7 & 497.12 & -0.47 & -0.58 \\
\hline 15.1 & 415.91 & 415.85 & -0.01 & -0.06 \\
\hline
\end{tabular}

Table 2. Table representing major observation from the results.

\begin{tabular}{ll}
\hline Parameter & Remark \\
\hline Total no. of observations & 46 \\
Maximum difference of Height from Strong Beam and Gauged data & $44 \mathrm{~cm}$ \\
Maximum difference of Height from Weak Beam and Gauged data & $52 \mathrm{~cm}$ \\
Root Mean Square Error form the observation using Strong Beam & $29 \mathrm{~cm}$ \\
Root Mean Square Error form the observation using Weak Beam & $34 \mathrm{~cm}$ \\
\hline
\end{tabular}

\section{Discussion}

As such ATL13 is a level 3B sub-product deduced from its master level 2 product ATL03 which primarily contains geolocated ellipsoidal heights for each time-tagged photon event downlinked from ATLAS sensor. Residual errors in ATL03 may have an impact on ATL13 data product at the centimeter level $[4,13]$. Conversion of preliminary ellipsoidal heights (WGS84 ellipsoid) from ATL03 to orthometric heights (EGM2008 Geoid) may also contribute certain quantities of minor errors at a centimeter level. Similarly, residual errors in the water height backscatter model that used in ATL13 and related algorithms may still influence the accuracies due to specular backscatter, Lambertian backscatter, solar Lambertian backscatter light from the water surface [13-14]. Also, shallow depths of many inland and nearshore water bodies result in possible bottom backscatter component to the overall water interaction [15].

Moreover, during the along-track data acquisition process there may be water waves that are generated due to local conditions like wind, capillary and gravity waves which may vary the height computed from ATL13 data product $[4,5]$.

In general, the results obtained from this investigation are similar to that of works done by Zhang et al. and Yuan et al. [6, 7]. However the analysis carried out in our study using 15 
reservoirs/water bodies, it appears that height retrieved from the strong beam is slightly better than that of height retrieved from the weak beams. The energy ratio between the strong beams and weak beams is approximately 1:4 and the nearsurface interaction phenomenon of photons emanating from the strong beams and weak beams of ICESat-2 may influence this difference. Figure 4 and figure 5 illustrate this phenomenon where elevations from weak beams are nearly 5 $\mathrm{cm}$ higher than elevations from strong beams.

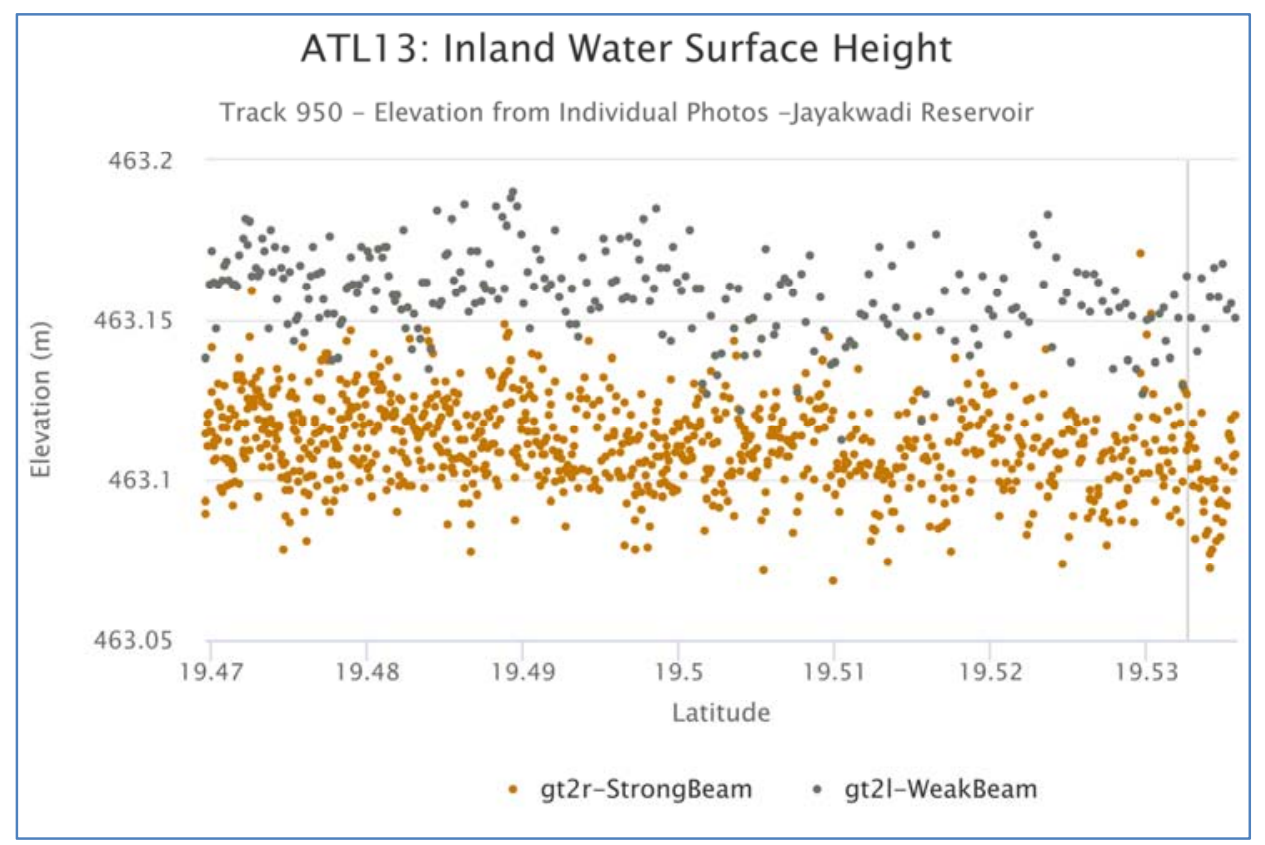

Figure 4. Variation of water interaction mechanism by photons from strong beam (gt2r) and weak beam (gt2l) of ICESat-2.

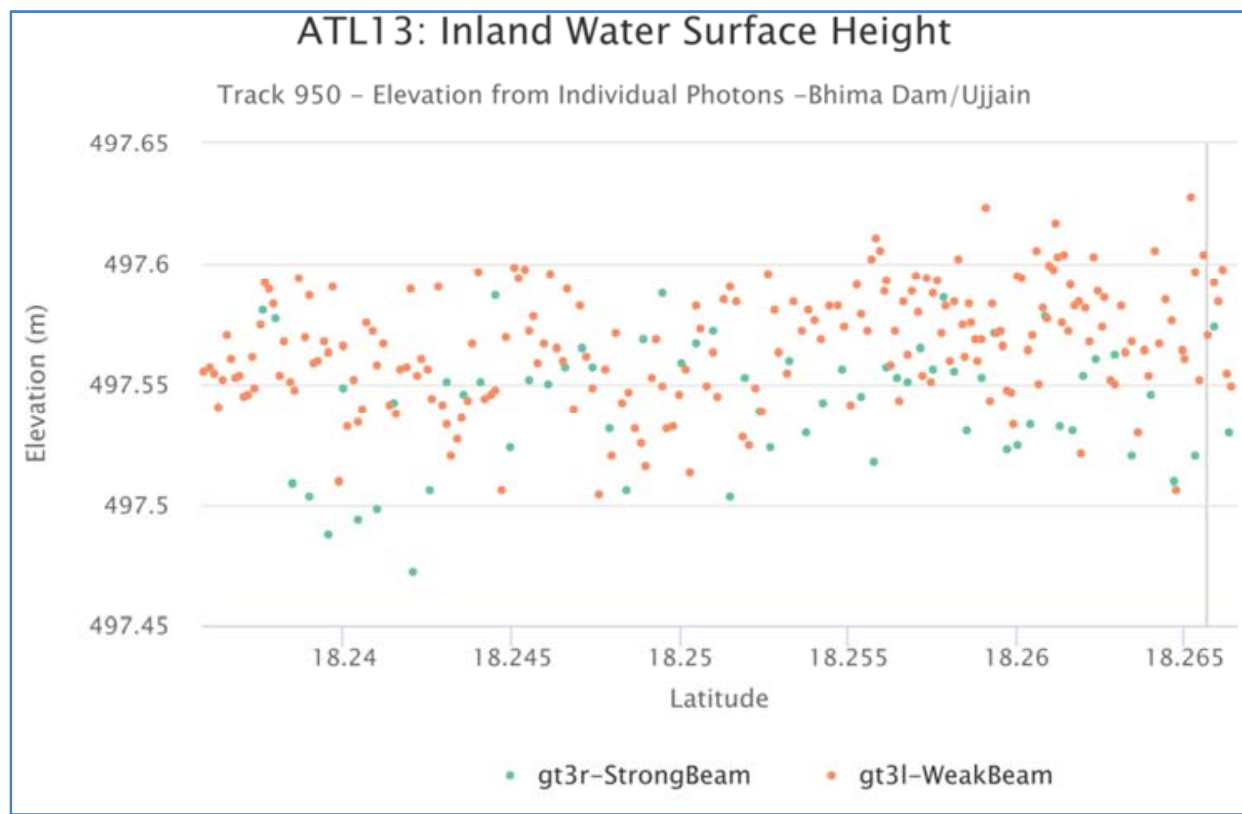

Figure 5. Variation of water interaction mechanism by photons from strong beam (gt3r) and weak beam (gt3l) of ICESat-2.

\section{Conclusion}

In this article, results after validating ICESat-2 ATL13 data product with near-real time gauged data have been presented. A total of 15 reservoirs/water bodies were investigated with 46 observations. The maximum uncertainty observed for the height of the surface water level retrieved from ICESat-2 ATL13 data product in terms of RMSE is $29 \mathrm{~cm}$ and $34 \mathrm{~cm}$ respectively for the segments of the strong beams and weak beams.

\section{Acknowledgements}

The Authors gratefully acknowledge Dr. C. S. Jha, Chief General Manager (Regional Centres) and Mr. Santanu Chowdhury, Director, National Remote Sensing Centre, 
Indian Space Research Organisation, Hyderabad, India for providing institutional support.

\section{References}

[1] Markus, T., Neumann, T., Martino, A., Abdalati, W., Brunt, K., Csatho, B., and Jasinski, M., "The Ice, Cloud, and land Elevation Satellite-2 (ICESat-2): science requirements, concept and implementation". Remote Sensing of Environment, 2017, 190, pp. $260-273$

[2] Brown, M. E., Arias, S. D., Neumann, T., Jasinski, M. F., Posey, P., Babonis, G., and Markus, T., "Applications for ICESat-2 Data: From NASA's Early Adopter Program". IEEE Geoscience and Remote Sensing Magazine, 2016, 4 (4), pp. 24-37.

[3] Alsdorf, D. E., Rodríguez, E. and Lettenmaier, D. P., "Measuring surface water from space". Reviews of Geophysics, 2007, 45 (2).

[4] Jasinski, M. F., J. D. Stoll, D. Hancock, J. Robbins, J. Nattala, J. Morison, B. M. Jones, M. E. Ondrusek, T. M. Pavelsky, C. Parrish, and the ICESat-2 Science Team., "ATLAS/ICESat-2 L3A Inland Water Surface Height, Version 3." Boulder, Colorado USA. NASA National Snow and Ice Data Center Distributed Active Archive Center. doi: https://doi.org/10.5067/ATLAS/ATL13.003.

[5] Dandabathula, G., Verma, M., Satyanarayana, P., and Rao, S. S., "Evaluation of ICESat-2 ATL08 Data Product: Performance Assessment in Inland Water". European Journal of Environment and Earth Sciences, 2020, 1 (3).

[6] Zhang, G., Chen, W., and Xie, H., "Tibetan Plateau's lake level and volume changes from NASA's ICESat/ICESat-2 and Landsat Missions". Geophysical Research Letters, 2019, 46 (22), pp. 13107-13118

[7] Yuan, C., Gong, P., and Bai, Y. "Performance Assessment of
ICESat-2 Laser Altimeter Data for Water-Level Measurement over Lakes and Reservoirs in China". Remote Sensing, 2020, $12(5), 770$.

[8] OpenAltimetry, "Open Altimetry: Advanced discovery, processing, and visualization services for ICESat and ICESat-2 altimeter data. (https://openaltimetry.org/).

[9] PDO, "Handbook for Hydrometeorological Observaitons. Planning and Development Organisation". Central Water Commission. 2020.

[10] CDSO, "Guidelines for Instrumentation of Large Dams. Central Dam Safety Organization, Central Water Commission. Doc. No.CDSO_GUD_DS_02_v1.0.2018.

[11] CWC Portal, "Central Water Commission", (http://cwc.gov.in/reservoir-storage).

[12] Messager, M. L., Lehner, B., Grill, G., Nedeva, I., and Schmitt, O. "Estimating the volume and age of water stored in global lakes using a geo-statistical approach. Nature communications, 2016, 7 (1), 1-11.

[13] Neumann, T., Brenner, A., Hancock, D., Robbins, J., Saba, J., Harbeck, K., and Gibbons, A., "Ice, Cloud, and land Elevation Satellite-2 (ICESat-2) Project: Algorithm Theoretical Basis Document (ATBD) for Global Geolocated Photons (ATL03)". National Aeronautics and Space Administration, Goddard Space Flight Center. 2019.

[14] Morison, J., Hancock, D., Dickinson, S., Robbins, J., Roberts, L., Kwok, R., Palm, S., Smith, B., Jasinski, M., Plant, B. and Urban, T., "Algorithm Theoretical Basis Document (ATBD) for Ocean Surface Height". National Aeronautics and Space Administration, Goddard Space Flight Center. 2019.

[15] Li, Y., Gao, H., Jasinski, M. F., Zhang, S. and Stoll, J. D., "Deriving high-resolution reservoir bathymetry from ICESat-2 prototype photon-counting lidar and Landsat imagery". IEEE Transactions on Geoscience and Remote Sensing, 2019, 57 (10), pp. 7883-7893. 